\title{
Mapping Disulfide Bonds in Insulin with the Route 66 Method: Selective Cleavage of $S-C$ Bonds Using Alkali and Alkaline Earth Metal Enolate Complexes
}

\author{
Hugh I. Kim* and J. L. Beauchamp \\ Noyes Laboratory of Chemical Physics, California Institute of Technology, Pasadena, California, USA
}

Simple and fast identification of disulfide linkages in insulin is demonstrated with a peptic digest using the Route 66 method. This is accomplished by collisional activation of singly and doubly charged cationic $\mathrm{Na}^{+}$and $\mathrm{Ca}^{2+}$ complexes generated using electrospray ionization mass spectrometry (ESI-MS). Collisional activation of doubly charged metal complexes of peptides with intermolecular disulfide linkages yields two sets of singly charged paired products separated by 66 mass units resulting from selective S-C bond cleavages. Highly selective elimination of 66 mass units, which corresponds to the molecular weight of hydrogen disulfide $\left(\mathrm{H}_{2} \mathrm{~S}_{2}\right)$, is observed from singly charged metal complexes of peptides with disulfide linkages. The mechanism proposed for these processes is initiated by formation of a metal-stabilized enolate at Cys, followed by cleavage of the S $-\mathrm{C}$ bond. Further activation of the products yields sequence information that facilitates locating the position of the disulfide linkages in the peptic digest fragments. For example, the doubly charged $\mathrm{Ca}^{2+}$ complex of the peptic digest product GIVEQCCASVCSL/FVNQHLCGSHL yields paired products separated by 66 mass units resulting from selective $S-C$ bond cleavages at an intermolecular disulfide linkage under low-energy collision-induced dissociation. Further activation of the product comprising the A chain reveals the presence of a second disulfide bridge, an intramolecular linkage. Experimental and theoretical studies of the disulfide linked model peptides provide mechanistic details for the selective cleavage of the $\mathrm{S}-\mathrm{C}$ bond. (J Am Soc Mass Spectrom 2009, 20, 157-166) (C) 2009 Published by Elsevier Inc. on behalf of American Society for Mass Spectrometry

$\mathrm{D}$ isulfide bonds are one of the most important post-translational modification (PTM) processes because of their unique role in determining the three-dimensional structures and stabilities of proteins [1-3]. Although various PTM sites in peptides have been identified using tandem mass spectrometry $\left(\mathrm{MS}^{n}\right)$ [4-11], disulfide bonds are not readily characterized by $\mathrm{MS}^{n}$ studies of protonated peptides [2]. Several studies achieved selective cleavages of the $S-S$ and $S-C$ bond at disulfide linkages using metal complexes of peptides [12-16]. Transition-metal $\left(\mathrm{Ni}^{2+}, \mathrm{Co}^{2+}\right.$, and $\left.\mathrm{Zn}^{2+}\right)$ complexes of oxytocin exhibit dissociation pathways related to $\mathrm{S}-\mathrm{S}$ and $\mathrm{S}-\mathrm{C}$ bond cleavages under electroncapture dissociation (ECD) conditions [14] and under sustained off-resonance irradiation collision-induced dissociation (SORI-CID) conditions [15]. Selective S-S bond cleavages in cationic gold(I) complexes of peptides under low-energy CID conditions were also re-

Address reprint requests to Dr. Jesse. L. Beauchamp, California Institute of Technology, Noyes Laboratory of Chemical Physics, Department of Chemistry, 1200 E. California Blvd., M/C 127-72, Pasadena, CA 91125, USA. E-mail: jlbchamp@caltech.edu

* Present address: Jet Propulsion Laboratory, California Institute of Technology, Pasadena, CA 91109. E-mail: hugh.i.kim@jpl.nasa.gov ported $[13,16]$. We have recently reported what we call the Route 66 method for locating disulfide bonds in peptides. This methodology is based on the highly selective elimination of $\mathrm{H}_{2} \mathrm{~S}_{2}$ (66 mass units) from singly charged sodiated and alkaline earth metal $\left(\mathrm{Mg}^{2+}\right.$ and $\mathrm{Ca}^{2+}$ ) bound peptide cations with disulfide linkages under CID conditions [12]. The process is initiated starting with a metal-stabilized enolate anion at Cys, followed by cleavage of the $\mathrm{S}-\mathrm{C}$ bond. Further $\mathrm{MS}^{n}$ spectra reveal additional details of the peptide structure in the region between the newly formed dehydroalanine $(\mathrm{dA})$ residues.

In this study, we report application of the Route 66 method for locating the position of disulfide linkages in insulin. This dipeptide hormone, widely used as a model system for the identification of disulfide bonds along with sequence information, offers the challenge of three closely spaced disulfide bonds, including both intramolecular and intermolecular linkages [17-19]. A number of studies have reported sequence analysis of insulin using mass spectrometry [19-23]. Complete sequence analysis of insulin was demonstrated using the reduced protein with low-energy CID [22]. ECD of the oxidized B-chain of insulin yields almost complete 
sequence information [23]. The CID of singly to triply charged insulin yields fragments resulting from intermolecular disulfide bond cleavages [19]. Although these top-down methods yield sequence information of insulin including the position of the Cys residues, locating the position of the original disulfide linkages in the protein remains a challenge. Analysis of a peptic digest is preferred for the investigation of this protein because the acidic $\mathrm{pH}$ preserves the original disulfide bonds [2]. Furthermore, pepsin attacks a wide range of amide linkages yielding product peptides involving cleavage between most Cys residues [18]. Our previous study reported that the electrospray ionization (ESI) mass spectrum from the pepsin digest of insulin shows eight major ion peaks, comprising five singly charged and three doubly charged ion peaks [12]. In the present investigation, we examine doubly charged $\mathrm{Na}^{+}$and $\mathrm{Ca}^{2+}$ complexes of the disulfide linked model peptide $(\mathrm{AARAAACAA})_{2}$ (MP2). Then, we demonstrate that collisional activation of cationic $\mathrm{Na}^{+}$and $\mathrm{Ca}^{2+}$ complexes of insulin peptic digest fragments allows for straightforward analysis of the disulfide linkages in the parent molecule. The mechanisms and energetics of the observed reactions are further examined by means of computational modeling. Structures of MP2 and insulin examined in this study are shown in Scheme $\mathbf{1 .}$

\section{Experimental}

Calcium dichloride $\left(\mathrm{CaCl}_{2}\right)$, insulin from bovine pancreas, iodine $\left(\mathrm{I}_{2}\right)$, pepsin from porcine stomach mucosa, and sodium chloride $(\mathrm{NaCl})$ were purchased from SigmaAldrich (St. Louis, MO, USA). The model peptide AARAAACAA was purchased from BiomerTechnology (Concord, CA, USA). All solvents (water, methanol, and benzene) were purchased from EMD Chemicals Inc. (Gibbstown, NJ, USA). For the formation of an intermolecular disulfide bond joining a dimer of the model peptide AARAAACAA, $10 \mathrm{mM}$ of the peptide in $300 \mu \mathrm{L}$ of water was mixed with $10 \mathrm{mM} \mathrm{I}_{2}$ in $300 \mu \mathrm{L}$ of benzene. The solution mixture was stirred vigorously for $30 \mathrm{~min}$ at room temperature. The aqueous solution was extracted after centrifugation. The sample solution was diluted to an appropriate concentration for ESI with 50:50 water/methanol solvent. The product corre-
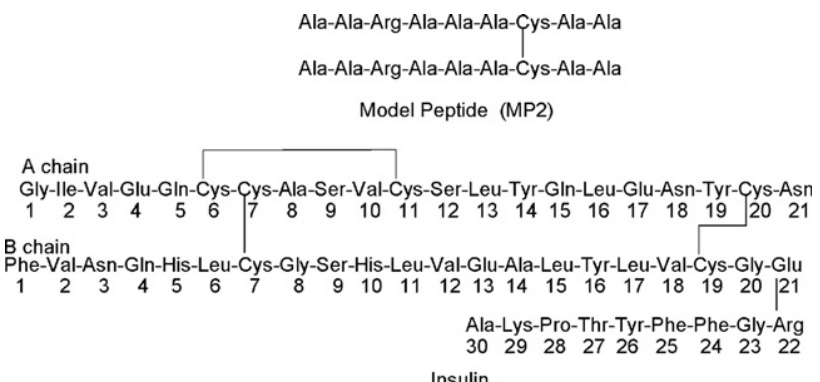
Insulin

Scheme 1. Structures of model peptide and insulin examined in this study. sponding to the dimeric peptide MP2 linked via a disulfide bond was confirmed by ESI mass spectrometric analysis. All metal complex samples were prepared by dissolving stoichiometric amounts of metal chloride and the analyte sample in the solvent. Total concentration of the sample solution was varied from 100 to 200 $\mu \mathrm{M}$. Pepsin digests of insulin were prepared by incubating $0.1 \mathrm{mg}$ of insulin from bovine pancreas with $0.025 \mathrm{mg}$ of pepsin from porcine stomach mucosa in water containing $1 \%$ acetic acid by volume at $37^{\circ} \mathrm{C}$ for $6 \mathrm{~h}$. Then pepsin was removed using a Microcon centrifugal filter (Millipore, Billerica, MA, USA) fitted with an Ultracel YM-10 membrane. The sample solution was diluted to an appropriate concentration for ESI. Metal complex samples were prepared by dissolving 40 $\mu \mathrm{M}$ metal chloride in the diluted peptic digest solution.

Experiments were performed on an LCQ Deca ion trap mass spectrometer (ITMS; ThermoFinnigan LLC, San Jose, CA, USA) in positive mode. Electrospray voltage parameters of $4.5 \mathrm{kV}$, capillary voltage of $8 \mathrm{~V}$, and capillary temperature $275{ }^{\circ} \mathrm{C}$ were set for ESI. The temperature of the MS analyzer was about $23^{\circ} \mathrm{C}$ before the experiment and about $24^{\circ} \mathrm{C}$ during the experiment. The pressure was estimated to be approximately $10^{-3}$ torr He inside the trap. Metal-complexed peptides of interest were isolated and fragmented via low-energy CID. Continuous isolation of selected ions followed by $\mathrm{CID}\left(\mathrm{MS}^{n}\right)$ was performed until the track of the isolated ion was lost. The ESI mass spectra reported in this study were obtained by averaging 30 scanned spectra.

The mechanisms and energetics of the $S-C$ bond and $S-S$ bond cleavage reactions were evaluated using density functional theory (DFT) calculations. Candidate structures for the $\mathrm{Ca}^{2+}$ complex of the dipeptide $(\mathrm{ACA})_{2}$ linked by a disulfide bond were generated using the AMBER (Assisted Model Building and Energy Refinement) force field by subjecting a starting conformation to 200 ps of dynamics at 500 $\mathrm{K}$, then cooling it to $50 \mathrm{~K}$ over a variable period of time using HyperChem 7.52 (Hypercube, Gainesville, FL, USA). For intermediates, 200 ps of dynamic simulation was executed at $300 \mathrm{~K}$ followed by cooling to $50 \mathrm{~K}$ over a variable period of time. The charge distribution of the complex was assigned at the PM3 level in each annealing sequence. Over 100 structures were generated and typically 20 candidate structures were determined. The lowest-energy structures were determined using DFT with the candidate structures. The DFT calculations were performed using Jaguar 6.0 (Schrödinger, Inc., Portland, OR, USA) utilizing the Becke three-parameter functional (B3) [24] combined with the correlation functional of Lee, Yang, and Parr (LYP) [25], using the LACVP basis set. Thermodynamic properties were calculated assuming ideal gas at $298.15 \mathrm{~K}$.

The nomenclature proposed by Roepstorff and Fohlman [26] was used for the parent and fragment ions. The prefixes dehydroalanine and $\Delta$ of parent ion (M) refer to peptide ions containing a disulfide bond and 
$\mathrm{dA}$, respectively. The numerical subscript refers to the number of units in the parent ion when more than one repeated monomeric unit exists in the ion. For example, a parent ion $(\mathrm{M})$ with two peptides, which are $\mathrm{X}$ and $\mathrm{Y}$, linked via two disulfide bonds is referred to as $d s_{2} M_{X Y}$. The dehydroalanine residue is referred to as $\mathrm{dA}$ in displayed peptide sequences. The element symbol superscript for the fragment ion refers to the metal cation in the singly charged metal complex of the fragment. For example, a $\mathrm{y}_{n}$ fragment ion complex with $\mathrm{Ca}^{2+}$ is referred to as $\mathrm{y}_{n}^{\mathrm{Ca}}$. The numerical subscript refers to the number of equivalent amino acid units in the fragment ions of metal complexes of the peptic peptides.

\section{Results and Discussion}

\section{Low-Energy CID of Metal Complexes of MP2}

We have recently demonstrated the low-energy CID of singly charged cationic $\mathrm{Na}^{+}$and $\mathrm{Ca}^{2+}$ complexes of MP2, which is the dimeric model peptide (AARAAACAA) 2 linked by an intermolecular disulfide bond [12]. The CID of the monosodiated MP2 yields the dominant product resulting from the elimination of $\mathrm{H}_{2} \mathrm{~S}_{2}(-66$ mass units) with monomeric products from the cleavages of the $\mathrm{S}-\mathrm{S}$ and $\mathrm{S}-\mathrm{C}$ bonds. A dramatic increase of the relative abundance of the product from the elimination of $\mathrm{H}_{2} \mathrm{~S}_{2}$ is observed from singly charged alkaline earth metal $\left(\mathrm{Ca}^{2+}\right.$ and $\left.\mathrm{Mg}^{2+}\right)$ complexes of MP2. In the present work we extend these earlier studies to include doubly charged cationic complexes of MP2, anticipating that the results can be useful in interpreting CID studies of the abundant doubly charged $\mathrm{Na}^{+}$and $\mathrm{Ca}^{2+}$ complexes observed in the ESI mass spectrum of the peptic digest of insulin.

Figure 1 shows $\mathrm{MS}^{n}$ spectra of doubly charged cationic complexes of MP2 with a $\mathrm{Na}^{+}$ion and a Ca ${ }^{2+}$ ion. The low-energy CID spectrum of the monosodiated peptide is shown in Figure 1a. The CID of the doubly charged sodiated peptide yields four distinct singly charged products. The products at $m / z 741.4$ and $\mathrm{m} / \mathrm{z}$ 807.2 are protonated product peptides and at $m / z 763.5$ and $m / z 829.3$ are monosodiated product peptides. Both paired protonated and sodiated products from MP2 are separated by 66 mass units, corresponding to the molecular weight of $\mathrm{H}_{2} \mathrm{~S}_{2}$. This results from the $\mathrm{S}-\mathrm{C}$ bond cleavage at the intermolecular disulfide linkage. The low-energy CID of doubly charged $\mathrm{Ca}^{2+}$ bound peptide yields highly selective cleavages of $\mathrm{S}-\mathrm{C}$ bonds. Two singly charged calcium bound products resulting from the $\mathrm{S}-\mathrm{C}$ bond cleavages are observed at $m / z 779.4$ and $m / z 845.2$ as well as two singly charged protonated products at $m / z 741.5$ and $m / z 807.2$ (Figure $1 b$ ). It is notable that only a minor product from the $S-S$ bond cleavage is observed at $\mathrm{m} / \mathrm{z} 775.4$ in the CID spectrum (Figure $1 \mathrm{~b}$ ). The $\mathrm{MS}^{3}$ spectra of the products at $m / z 779.4$ and $m / z 741.5$ are shown in Figure $1 c$ and $d$, respectively. The $\mathrm{MS}^{3}$ spectrum of the $\mathrm{Ca}^{2+}$ bound product at $\mathrm{m} / \mathrm{z} 779.4$ exhibits the dominant product resulting from

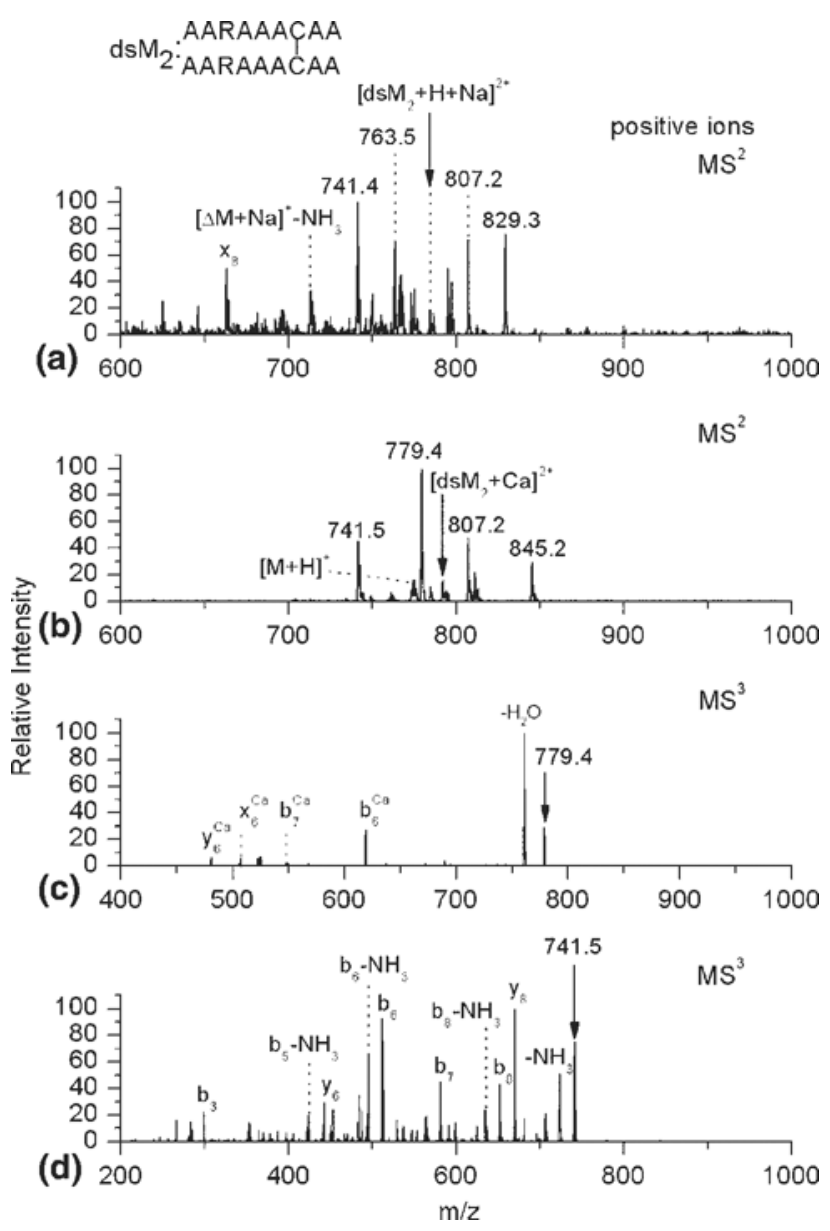

Figure 1. CID spectra of doubly charged (a) monosodiated MP2 and (b) monocalcium bound MP2 showing dominant product pairs separated by 66 mass units. (c) $\mathrm{MS}^{3}$ spectrum of the $\mathrm{MS}^{2}$ product at $\mathrm{m} / \mathrm{z} 779.4$ from (b). (d) $\mathrm{MS}^{3}$ spectrum of the $\mathrm{MS}^{2}$ product at $m / z 741.5$ from (b). Arrows indicate the ion peaks being isolated and collisionally activated.

dehydration (Figure 1c). Other than dehydration, the products comprise b-type fragments $\left(b_{6}\right.$ and $\left.b_{7}\right)$ formed by cleavages on both sides of the $\mathrm{dA}$ residue. The collisionally activated protonated product at $\mathrm{m} / \mathrm{z} 741.5$ dissociates to yield a broad range of $b$ - and y-type fragments. Similar to the $\mathrm{MS}^{3}$ of the product at $\mathrm{m} / \mathrm{z}$ 779.4, b-type fragments $\left(b_{6}\right.$ and $\left.b_{7}\right)$ formed by cleavages on both sides of the $\mathrm{dA}$ residue are observed in the $\mathrm{MS}^{3}$ spectrum of the product at $m / z 741.5$ (Figure 1d).

\section{Low-Energy CID of Metal Complexes of the Pepsin Digest of Insulin}

The ESI mass spectrum of pepsin digest of insulin exhibits eight major ion peaks that show good agreement with earlier published analyses (Table 1) [17, 18]. The masses and segments of observed metallated peptic digest ions of insulin with added sodium and calcium are included in Table 1. 
Table 1. Major peptide ions in the mass spectrum of the 6-h pepsin digest of insulin

\begin{tabular}{|c|c|c|c|c|c|}
\hline Segment ${ }^{a, b}$ & Sequence $^{b}$ & Charge state & Protonated & $m / z$ Sodiated & Calcium \\
\hline B26-30 & YTPKA & +1 & 579.3 & $\begin{array}{l}601.4^{\mathrm{c}} \\
623.5^{\mathrm{d}}\end{array}$ & $617.3^{\mathrm{e}}$ \\
\hline B25-30 & FYTPKA & +1 & 726.4 & $\begin{array}{l}748.5^{\mathrm{c}} \\
770.4^{\mathrm{d}}\end{array}$ & $-^{g}$ \\
\hline B23-30 & GFFYTPKA & +1 & 931.2 & $953.3^{\mathrm{c}}$ & $-{ }^{\mathrm{g}}$ \\
\hline A14-21/B17-25 & YQLENYCN/LVCGERGFF & +2 & 1036.4 & $\begin{array}{l}1047.4^{\mathrm{c}} \\
1074.0^{\mathrm{f}}\end{array}$ & $1055.5^{e}$ \\
\hline $\mathrm{A} 1-13 / \mathrm{B} 1-11$ & GIVEOCCASVCSL/FVNOHLCGSHL & +2 & 1281.6 & $\begin{array}{l}1292.5^{\mathrm{c}} \\
1303.6^{\mathrm{d}}\end{array}$ & $\begin{array}{l}1300.5^{e} \\
1319.6^{f}\end{array}$ \\
\hline A1-13/B1-13 & GIVEOCCASVCSL/FVNOHLCGSHLVE & +2 & 1395.5 & $\begin{array}{l}1406.5^{\mathrm{c}} \\
1417.5^{\mathrm{d}}\end{array}$ & $\begin{array}{l}1415.1^{\mathrm{e}} \\
1434.1^{\mathrm{f}}\end{array}$ \\
\hline $\begin{array}{l}\mathrm{A} 18-21 / \mathrm{B} 17-25 \\
\mathrm{~A} 16-21 / \mathrm{B} 17-25\end{array}$ & $\begin{array}{l}\text { NYCN/LVCGERGFF } \\
\text { LENYCN/LVCGERGFF }\end{array}$ & $\begin{array}{l}+1 \\
+1\end{array}$ & $\begin{array}{l}1537.6 \\
1779.5\end{array}$ & $\begin{array}{l}1559.5^{\mathrm{c}} \\
1801.5^{\mathrm{c}, \mathrm{g}}\end{array}$ & $\begin{array}{l}-9 \\
-9\end{array}$ \\
\hline
\end{tabular}

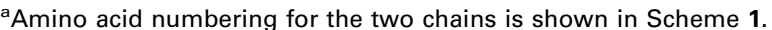

beptide pair with disulfide linkage is indicated with "/".

cMonosodiated ion.

${ }^{\mathrm{d} D i s o d i a t e d}$ ion.

eMonocalcium bound ion.

fDicalcium bound ion.

${ }^{9}$ Because of the low intensity of this fragment, the metal complex species was not observed or not sufficiently abundant for MS ${ }^{2}$ analysis.

\section{Singly Charged Sodiated Peptides from Pepsin Digest of Insulin}

As summarized in Table 1, abundant singly charged sodiated peptide ions are observed for three peptic digest products from insulin, which correspond to YTPKA, FYTPKA, and NYCN/LVCGERGFF. By scanning $\mathrm{MS}^{2}$ of singly charged sodiated peptic digest components for loss of 66 mass units $\left(\mathrm{H}_{2} \mathrm{~S}_{2}\right)$ it is possible to identify peptide fragments with disulfide linkages. CID of sodiated peptides YTPKA at $\mathrm{m} / \mathrm{z} 601.2$ and FYTPKA at $m / z 748.5$ yield major products resulting commonly from the elimination of C-terminal Ala (-89 mass units). No product is found from the elimination of $\mathrm{H}_{2} \mathrm{~S}_{2}$ (-66 mass units). Results for CID of monosodiated dipeptide NYCN/LVCGERGFF at $\mathrm{m} / \mathrm{z}$ 1559.5, linked via an intermolecular disulfide bond, were presented in our earlier study [12]. The CID of sodiated NYCN/LVCGERGFF yields a major product from $\mathrm{H}_{2} \mathrm{~S}_{2}$ elimination. The observed elimination of $\mathrm{H}_{2} \mathrm{~S}_{2}$ indicates the presence of a disulfide linkage in the peptide.

\section{Doubly Charged Sodiated Peptides from Pepsin Digest of Insulin}

Abundant doubly charged sodiated peptide ions are observed for three peptic digest products YQLENYCN/ LVCGERGFF, GIVEQCCASVCSL/FVNQHLCGSHL, and GIVEQCCASVCSL/FVNQHLCGSHLVE (Table 1). Figure 2 shows CID spectra of the major doubly charged sodiated peptic digest fragments (Table 1) of insulin. The CID of doubly charged monosodiated dipeptide YQLENYCN/LVCGERGFF yields abundant products resulting from dehydration and combined dehydration and ammonia elimination (Figure 2a). In addition, a minor product from the elimination of A-chain C-terminal Asn is observed in the spectrum.
The product at $m / z 1059.3$ is the singly charged, protonated B-chain peptide, with $-\mathrm{SSH}$ replacing $-\mathrm{SH}$ at Cys.

Figure $2 \mathrm{~b}$ shows the CID spectrum of the doubly charged disodiated dipeptide GIVEQCCASVCSL/ FVNQHLCGSHL. This dipeptide is linked by one intermolecular disulfide bond between ${ }^{\mathrm{A}} \mathrm{Cys}_{7}$ and ${ }^{\mathrm{B}} \mathrm{Cys}_{7}$. In addition, the A-chain peptide contains one intramolecular linkage between ${ }^{\mathrm{A}} \mathrm{Cys}_{6}$ and ${ }^{\mathrm{A}} \mathrm{Cys}_{11}$. Various products, resulting from dehydrations $(\mathrm{m} / \mathrm{z} 1285.5$ and $\mathrm{m} / \mathrm{z}$ $1276.5)$, the $S-S$ bond cleavage $(\mathrm{m} / z$ 1329.3), the Cterminal residue elimination $(\mathrm{m} / \mathrm{z}$ 1246.5), and cleavages at Asp residue $(\mathrm{m} / \mathrm{z} 1104$ and $\mathrm{m} / \mathrm{z}$ 1095.3), are observed in the spectrum. In addition, CID of the doubly charged disodiated dipeptide yields four distinct singly charged monosodiated products at $\mathrm{m} / \mathrm{z} 1242.5, \mathrm{~m} / \mathrm{z} 1297.3, \mathrm{~m} / \mathrm{z}$ 1308.3, and $\mathrm{m} / \mathrm{z}$ 1363.3. The products at $\mathrm{m} / \mathrm{z} 1242.5$ and $\mathrm{m} / \mathrm{z} 1308.3$ are separated by 66 mass units. The products result from the conversion of Cys into dA $(\mathrm{m} / \mathrm{z}$ 1242.5) and disulfide group $(\mathrm{m} / \mathrm{z}$ 1308.3) from A-chain peptide via S $-\mathrm{C}$ bond cleavage. The products at $\mathrm{m} / \mathrm{z} 1297.3$ and $\mathrm{m} / \mathrm{z} 1363.3$ result from conversion of Cys into either a $\mathrm{dA}$ or a disulfide group on the B-chain peptide. The product resulting from the eliminations of two $\mathrm{H}_{2} \mathrm{~S}_{2}$ indicates two disulfide linkages in the dipeptide.

The dipeptide GIVEQCCASVCSL/FVNQHLCGSHLVE contains one intermolecular linkage between ${ }^{\mathrm{A}} \mathrm{Cys}_{7}$ and ${ }^{\mathrm{B}} \mathrm{Cys}_{7}$ along with intramolecular linkage between ${ }^{\mathrm{A}} \mathrm{Cys}_{6}$ and ${ }^{\mathrm{A}} \mathrm{Cys}_{11}$. The CID spectrum of doubly charged disodiated GIVEQCCASVCSL/FVNQHLCGSHLVE is shown in Figure 2c. The product resulting from the eliminations of two $\mathrm{H}_{2} \mathrm{~S}_{2}$ is observed at $\mathrm{m} / \mathrm{z}$ 1352.5. Two singly charged monosodiated products separated by 66 mass units are observed at $\mathrm{m} / \mathrm{z} 1297.4$ and $\mathrm{m} / \mathrm{z} 1363.4$ from the B-chain peptide. The other two singly charged monosodiated products separated by 66 mass units are 


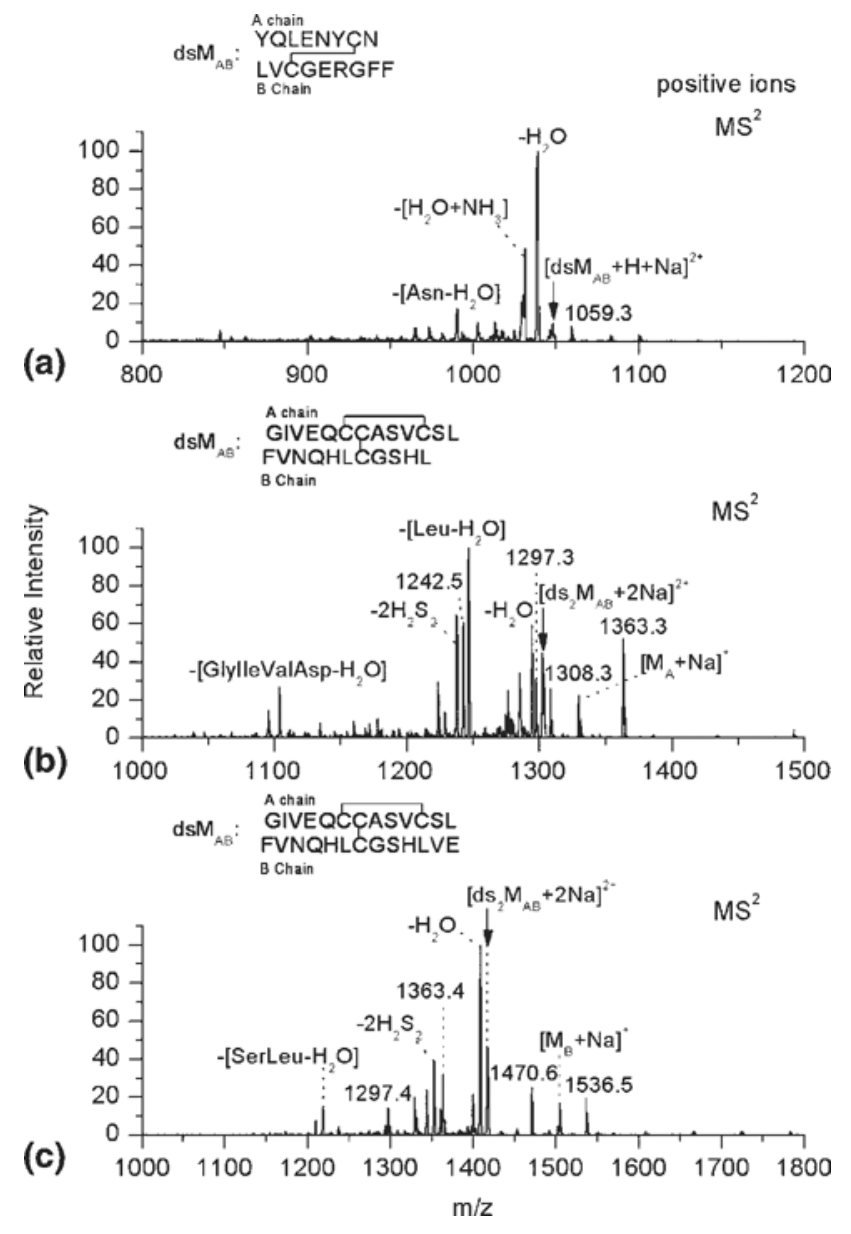

Figure 2. (a) $\mathrm{MS}^{2}$ spectrum of doubly charged monosodiated peptic digest fragment from insulin YQLENYCN/LVCGERGFF. (b) $\mathrm{MS}^{2}$ spectrum of doubly charged disodiated peptic digest fragment from insulin GIVEQCCASVCSL/FVNQHLCGSHL, showing major products involving disulfide bond cleavages. (c) $\mathrm{MS}^{2}$ spectrum of doubly charged disodiated peptic digest fragment from insulin GIVEQCCASVCSL/FVNQHLCGSHLVE, showing major products involving disulfide bond cleavages. Arrows indicate the ion peaks being isolated and collisionally activated.

observed at $\mathrm{m} / \mathrm{z} 1470.6$ and $\mathrm{m} / \mathrm{z} 1536.5$ from the A-chain peptide.

\section{Doubly Charged Calcium Complexes of Peptides from Pepsin Digest of Insulin}

The observed calcium bound pepsin digest of insulin from the ESI mass spectrum is summarized in Table 1. Abundant doubly charged calcium complexes are observed for three peptic digest products YQLENYCN/ LVCGERGFF, GIVEQCCASVCSL/FVNQHLCGSHL, and GIVEQCCASVCSL/FVNQHLCGSHLVE. Figures 3-5 show low-energy CID spectra of doubly charged $\mathrm{Ca}^{2+}$ bound peptides YQLENYCN/LVCGERGFF, GIVEQCCASVCSL/FVNQHLCGSHL, and GIVEQCCASVCSL/ FVNQHLCGSHLVE.

\section{Doubly Charged Dicalcium Complex of YQLENYCN/LVCGERGFF}

As seen in Figure 3a, CID of doubly charged dicalcium bound dipeptide YQLENYCN/LVCGERGFF yields four distinct products. The products at $\mathrm{m} / \mathrm{z} 1116.2$ and $\mathrm{m} / \mathrm{z}$ 1050.2 and the products at $\mathrm{m} / \mathrm{z} 1097.2$ and $\mathrm{m} / \mathrm{z} 1031.4$ are separated by 66 mass units. The two sets of products indicate the presence of an intermolecular disulfide linkage in the peptide. The products at $\mathrm{m} / \mathrm{z} 1116.2$ and $\mathrm{m} / \mathrm{z} 1050.2$ are singly charged monocalcium bound A-chain peptides with Cys converted to a disulfide and a dehydroalanine, respectively, via $\mathrm{S}-\mathrm{C}$ bond cleavages. The products at $\mathrm{m} / \mathrm{z} 1097.2$ and $\mathrm{m} / \mathrm{z} 1031.4$ are a singly charged monocalcium bound B-chain peptide with a disulfide and a dehydroalanine, respectively. Further $\mathrm{MS}^{n}$ analysis was performed to locate the position of the disulfide linkage in the dipeptide.

Figure $3 \mathrm{~b}$ shows the $\mathrm{MS}^{3}$ spectrum of the product at $\mathrm{m} / \mathrm{z}$ 1116.2. The major product observed at $\mathrm{m} / \mathrm{z} 1050.4$ results from elimination of $\mathrm{H}_{2} \mathrm{~S}_{2}$. The $\mathrm{MS}^{3}$ product at

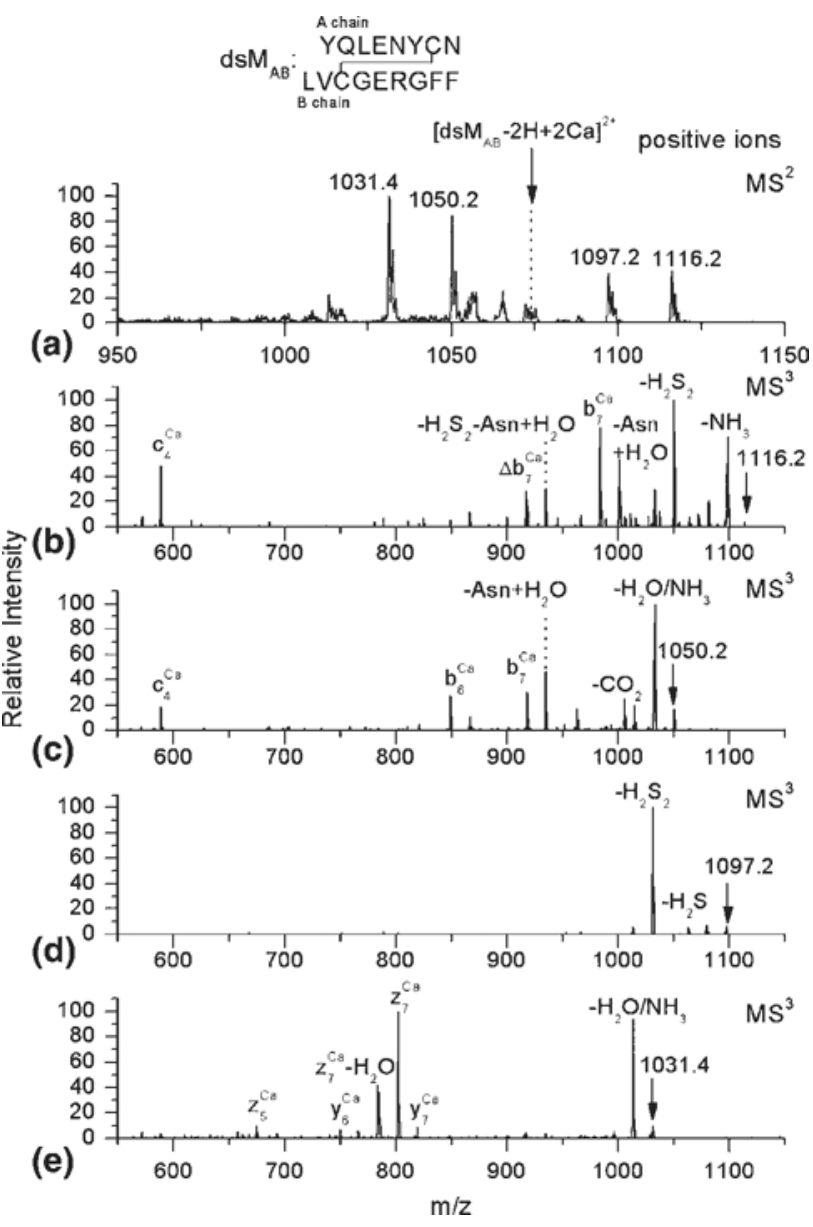

Figure 3. (a) CID spectrum of doubly charged dicalcium bound peptic digest fragment from insulin YQLENYCN/LVCGERGFF. (b) $\mathrm{MS}^{3}$ of product at 1116.2 from (a). (c) $\mathrm{MS}^{3}$ of product at 1050.2 from (a). (d) $\mathrm{MS}^{3}$ of product at 1097.2 from (a). (e) $\mathrm{MS}^{3}$ of product at 1031.4 from (a). Arrows indicate the ion peaks being isolated and collisionally activated. 
$m / z 1050.4$ confirms that the $\mathrm{MS}^{2}$ product at $m / z 1116.2$ contains a disulfide group via the $\mathrm{S}-\mathrm{C}$ bond cleavage. Products resulting from $\mathrm{C}$-terminal Asn elimination are observed at $m / z 935.2\left(-\mathrm{H}_{2} \mathrm{~S}_{2}-\mathrm{Asn}+\mathrm{H}_{2} \mathrm{O}\right)$ and $m / z$ 1001.5 (-Asn $+\mathrm{H}_{2} \mathrm{O}$ ). The products comprise b-type fragments $\left(b_{7}\right.$ and $\left.b_{7}-\mathrm{H}_{2} \mathrm{~S}_{2}\right)$ formed by cleavage at the disulfide site. A significant fragment $\mathrm{c}_{4}$ is also observed at $m / z$ 589.2. The $\mathrm{MS}^{3}$ spectrum of the product at $\mathrm{m} / \mathrm{z}$ 1050.2 is shown in Figure 3c. Similar to the $\mathrm{MS}^{3}$ spectrum of the peptide at $m / z 1116.2$, the spectrum exhibits products resulting from C-terminal Asn elimination and the $c_{4}$ fragment. No product resulting from the elimination of $\mathrm{H}_{2} \mathrm{~S}_{2}$ is observed, indicating the absence of a disulfide group in the peptide. Two b-type fragments $\left(b_{6}\right.$ and $\left.b_{7}\right)$ at dehydroalanine residues locate the position of the intermolecular disulfide linkage in the A-chain peptide.

Figure $3 \mathrm{~d}$ and e show $\mathrm{MS}^{3}$ spectra of the $\mathrm{MS}^{2}$ products at $m / z 1097.2$ and $m / z 1031.4$ from the B-chain peptide. The $\mathrm{MS}^{3}$ of the product at $m / z 1097.2$ yields the exclusive product at $\mathrm{m} / \mathrm{z} 1031.3$ resulting from elimination of $\mathrm{H}_{2} \mathrm{~S}_{2}$. The $\mathrm{MS}^{3}$ spectrum of the $\mathrm{MS}^{2}$ product at $\mathrm{m} / \mathrm{z} 1031.4$ yields $\mathrm{z}$ - and y-type fragments. Formation of $\mathrm{y}_{6}$ and $\mathrm{y}_{7}$ fragments at the dehydroalanine residue locates the position of the disulfide linkage in the B-chain peptide. In addition, products comprising $\mathrm{Z}$ type fragments $\left(z_{5}\right.$ and $\left.z_{7}\right)$ are observed in the spectrum. CID pathways of the doubly charged dicalcium bound YQLENYCN/LVCGERGFF cation are summarized in Scheme 2.

\section{Doubly Charged Dicalcium Complex of GIVEQCCASVCSL/FVNQHLCGSHL}

The $\mathrm{MS}^{2}$ spectrum of the doubly charged dicalcium bound GIVEQCCASVCSL/FVNQHLCGSHL peptide shows two distinct products at $\mathrm{m} / \mathrm{z} 1379.4$ and $\mathrm{m} / \mathrm{z}$ 1258.4 (Figure 4a). A product separated by 66 mass units from the product at $m / z 1379.4$ is observed at $m / z$ 1313.3. The $\mathrm{MS}^{2}$ products at $\mathrm{m} / z 1379.4$ and $\mathrm{m} / \mathrm{z} 1313.3$ are a singly charged monocalcium bound peptide from the A-chain peptide with Cys converted to a disulfide and dehydroalanine, respectively. A product separated

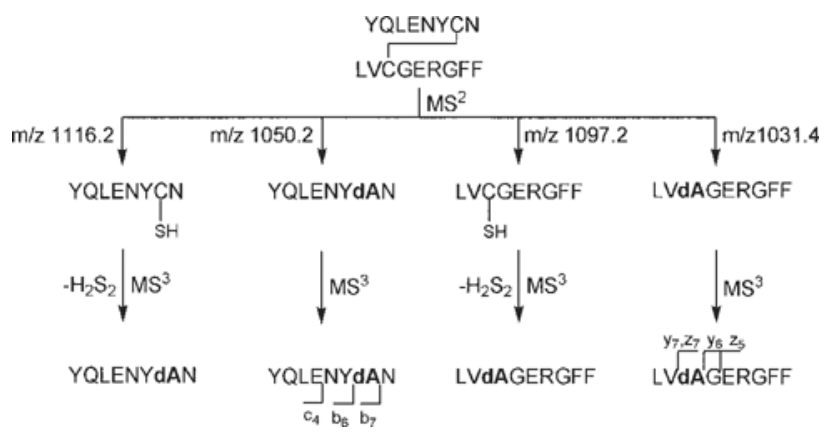

Scheme 2. Dissociation pathways of doubly charged dicalcium bound peptic peptide of insulin YQLENYCN/LVCGERGFF inferred from CID. Indicated product probed by $\mathrm{MS}^{3}$.

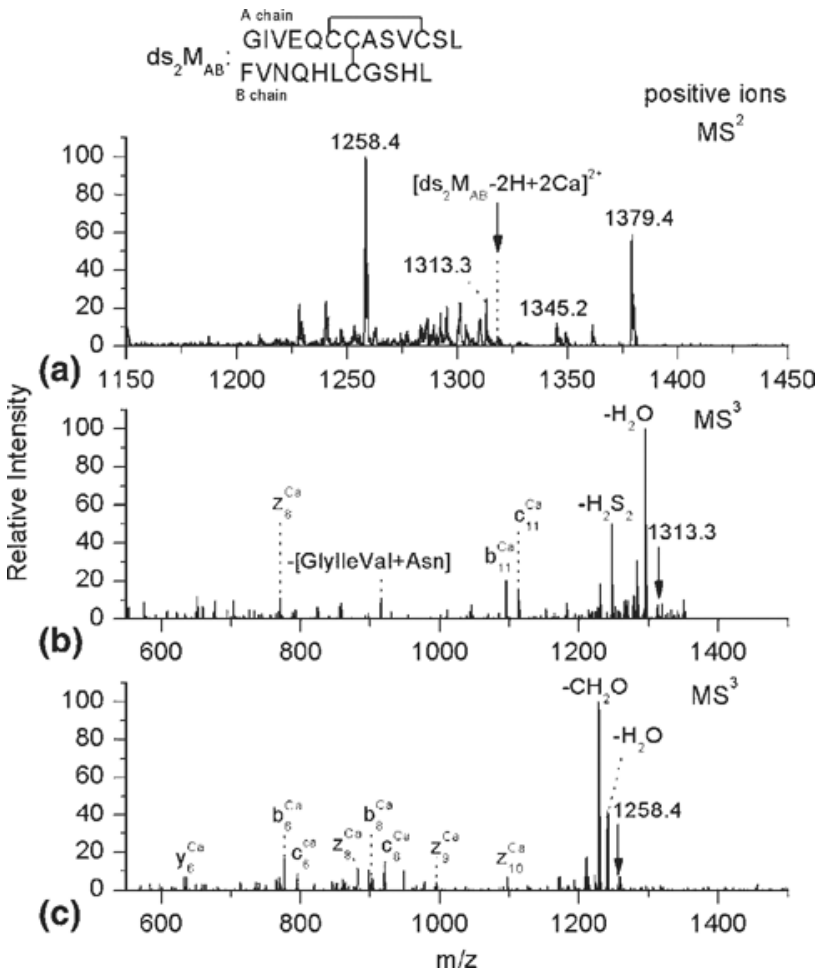

Figure 4. (a) CID spectrum of doubly charged dicalcium bound peptic digest fragment from insulin GIVEQCCASVCSL/ FVNQHLCGSHL. (b) $\mathrm{MS}^{3}$ of product at 1313.3 from (a). (c) $\mathrm{MS}^{3}$ of product at 1258.4 from (a). Arrows indicate the ion peaks being isolated and collisionally activated.

by 66 mass units from the product at $m / z 1258.4$ is not observed in the spectrum. The product at $\mathrm{m} / \mathrm{z} 1258.4$ is the singly charged monocalcium bound peptide with dehydroalanine from the B-chain peptide.

Figure $4 \mathrm{~b}$ shows the $\mathrm{MS}^{3}$ spectrum of the $\mathrm{MS}^{2}$ product at $m / z$ 1313.3. Other than a dehydration product, an ion resulting from the elimination of $\mathrm{H}_{2} \mathrm{~S}_{2}$ is observed as a major product in the $\mathrm{MS}^{3}$ spectrum. Of note, the $\mathrm{MS}^{2}$ product at $\mathrm{m} / \mathrm{z} 1313.3$ contains a dehydroalanine residue converted from $C y s$ via the $S-C$ bond cleavage. The dipeptide GIVEQCCASVCSL/ FVNQHLCGSHL contains one intermolecular linkage and one intramolecular disulfide linkage. From this it is inferred that the observed selective elimination of $\mathrm{H}_{2} \mathrm{~S}_{2}$ is from the intramolecular disulfide linkage in the A-chain peptide. The observation of $b_{11}$ and $c_{11}$ fragments at ${ }^{\mathrm{A}} \mathrm{Cys}_{11}$ and $\mathrm{z}_{8}$ fragment at ${ }^{\mathrm{A}} \mathrm{Cys}_{6}$ locate the position of the intramolecular disulfide linkage. Figure 4c shows the $\mathrm{MS}^{3}$ spectrum of the $\mathrm{MS}^{2}$ product at $\mathrm{m} / \mathrm{z}$ 1258.4. The major product at $m / z 1228.3$ results from the elimination of $\mathrm{CH}_{2} \mathrm{O}$ ( -30 mass units) from ${ }^{\mathrm{B}} \mathrm{Ser}_{9}$. The products comprising b-type $\left(b_{6}\right.$ and $\left.b_{8}\right)$ and c-type $\left(c_{6}\right.$ and $c_{8}$ ) fragments locate the position of the intramolecular disulfide linkage. Other products from ztype fragments are also observed. All observed CID pathways of the doubly charged dicalcium bound GIVEQCCASVCSL/FVNQHLCGSHL cation are summarized in Scheme 3. 


\section{Doubly Charged Dicalcium Complex of GIVEQCCASVCSL/FVNQHLCGSHLVE}

Figure 5a shows the CID spectrum of the doubly charged dicalcium bound GIVEQCCASVCSL/FVNQHLCGSHLVE cation. In analogy to other doubly charged metal complex dipeptides with intermolecular disulfide bonds, four distinct products are observed via CID. The abundant products at $\mathrm{m} / \mathrm{z} 1486.6$ and $\mathrm{m} / \mathrm{z} 1552.6$ originate from the $B$ chain and are separated by 66 mass units. The A-chain peptide is also observed at $\mathrm{m} / \mathrm{z} 1151$. The two products at $m / z 1379.3$ and $m / z 1313.5$ from the A-chain peptide were discussed in the previous section.

The $\mathrm{MS}^{3}$ spectrum of the product at $m / z 1486.6$ yields a major product resulting from dehydration (Figure $5 b$ ). The product from the elimination of C-terminal Glu is observed at $m / z$ 1357.6. The products comprising $x_{7}$ and $\mathrm{y}_{7}$ fragments at the dehydroalanine residue are also observed. Combined with the $c_{8}$ fragment, the $x_{7}$ and $y_{7}$ fragments locate the position of the disulfide linkage in the B-chain peptide. The CID pathways of the doubly charged dicalcium bound GIVEQCCASVCSL/ FVNQHLCGSHLVE cation are summarized in Scheme 4.

\section{Selective S-C Bond Cleavage Processes Involving Enolate at Cys}

This study demonstrates selective $S-C$ bond cleavage of doubly charged sodiated and calcium bound disulfide linked dipeptide cations under low-energy CID conditions. As seen in Figure 1, only a minor product is yielded by the $S-S$ bond cleavage process. As we proposed, the formation of an enolate anion at the Cys residue initiates the selective elimination of $\mathrm{H}_{2} \mathrm{~S}_{2}$ from singly charged metal complex peptides under lowenergy CID [12]. The selective $S-C$ bond cleavage from doubly charged collisionally activated metal complex peptides is considered to be initiated from an enolate structure at the Cys residue (Scheme 5). As seen in Figure $1 \mathrm{c}$ and $\mathrm{d}$, the $\mathrm{MS}^{3}$ products comprise b-type fragments $\left(b_{6}\right.$ and $\left.b_{7}\right)$ formed by cleavage between the dehydroalanine $(\mathrm{dA})$ residue from MP2. This suggests that the hydrogen atoms attached to the sulfur atoms

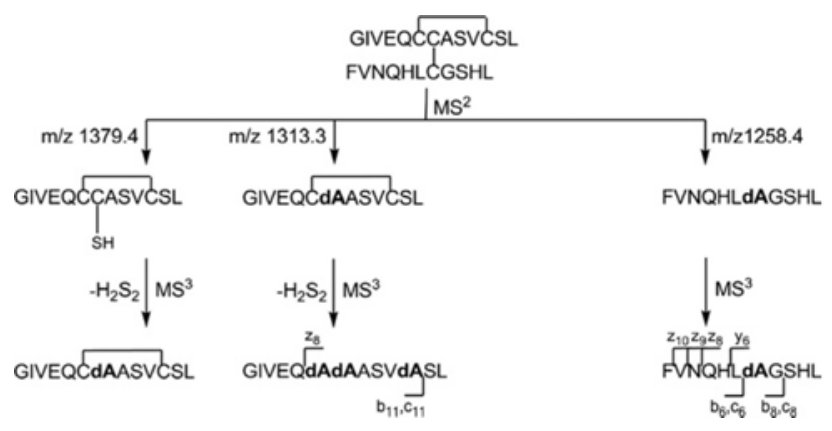

Scheme 3. Dissociation pathways of doubly charged dicalcium bound peptic peptide of insulin GIVEQCCASVCSL/FVNQHLCGSHL inferred from CID. Indicated product probed by $\mathrm{MS}^{3}$.

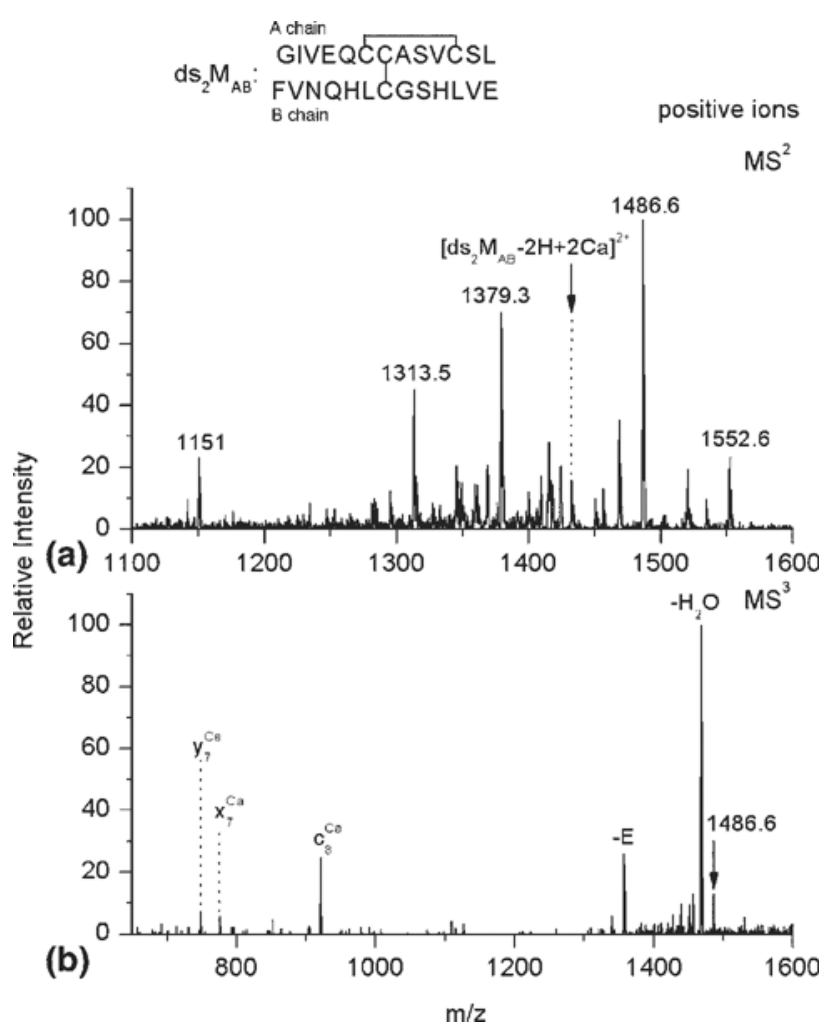

Figure 5. (a) CID spectrum of doubly charged dicalcium bound peptic digest fragment from insulin GIVEQCCASVCSL/ FVNQHLCGSHLVE. (b) $\mathrm{MS}^{3}$ of product at 1486.6 from (a). Arrows indicate the ion peaks being isolated and collisionally activated.

originated from the $\alpha$-carbon of Cys as a result of the enolation process.

Figure 6 shows the DFT calculated changes of electronic energy $(\Delta \mathrm{E})$ associated with cleavages involving $\mathrm{S}-\mathrm{S}$ and $\mathrm{S}-\mathrm{C}$ bonds in the $\mathrm{Ca}^{2+}$ bound dimeric peptide, $(\mathrm{ACA})_{2}$, linked by an intermolecular disulfide bond. The optimized geometries of the corresponding intermediates are shown below the diagram. The $S-S$ bond cleavage process of calcium bound $(\mathrm{ACA})_{2}$ is endothermic by approximately $113 \mathrm{~kJ} / \mathrm{mol}$. However, the process is exothermic overall for the $S-C$ bond cleavage. The intermediate species associated with the $\mathrm{S}-\mathrm{C}$ bond cleavage are energetically favored by about

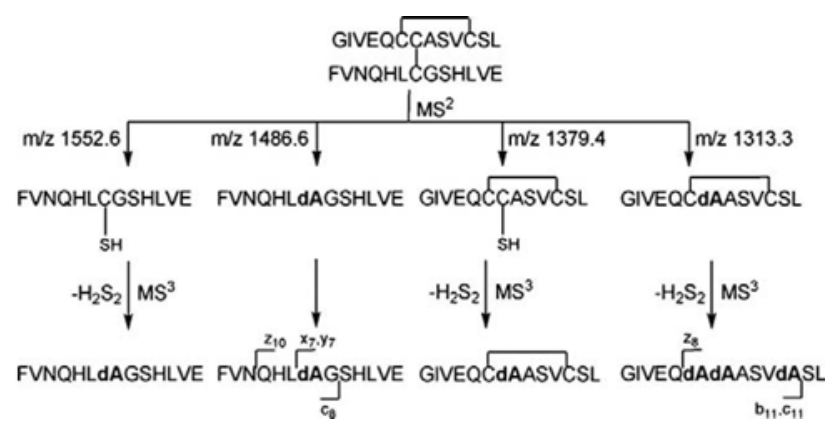

Scheme 4. Dissociation pathways of doubly charged dicalcium bound peptic peptide of insulin GIVEQCCASVCSL/FVNQHLCGSHLVE inferred from CID. Indicated product probed by $\mathrm{MS}^{3}$. 

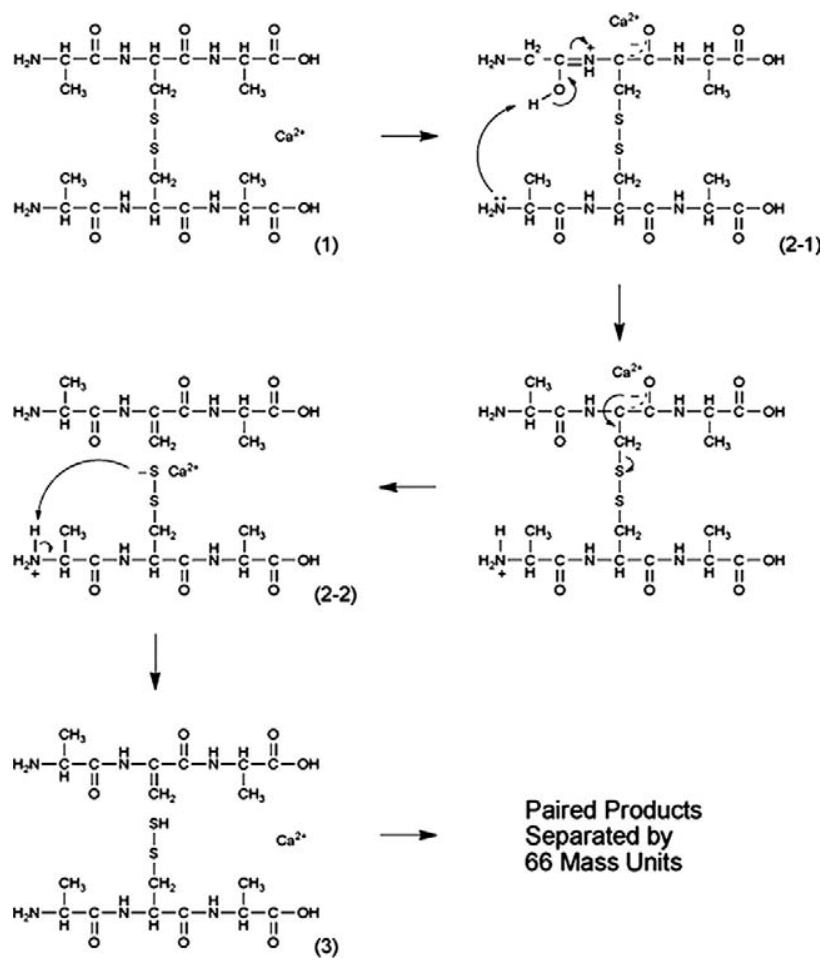

Paired Products
Separated by 66 Mass Units

Scheme 5. Proposed S $-\mathrm{C}$ bond cleavage mechanisms of doubly charged cationic $\mathrm{Ca}^{2+}$ bound dipeptide (ACA) $)_{2}$ linked by intermolecular disulfide bond. Optimized geometries and energy changes for corresponding numbered states of $\mathrm{Ca}^{2+}$ bound $(\mathrm{ACA})_{2}$ are shown in Figure 6.

$210 \mathrm{~kJ} / \mathrm{mol}$ compared with intermediates involved in the cleavage of the $\mathrm{S}-\mathrm{S}$ bond. The $\mathrm{S}-\mathrm{C}$ bond cleavage is initiated by enolate at Cys and stabilized by interaction of a $\mathrm{Ca}^{2+}$ ion with the disulfide group. The proton transfer from the $\mathrm{N}$-terminal amine to the disulfide group allows the $\mathrm{Ca}^{2+}$ ion to interact mainly with the amide/carboxylic acid oxygen atoms. Once the proton is transferred to the disulfide group, immediate separation of the two fragments occurs as the result of a charge repulsion and both are observed in the $\mathrm{MS}^{2}$ spectrum (Figure $1 \mathrm{~b}$ ). The $S-S$ bond cleavage process requires unfavorable proton transfer from the $\beta$-carbon at $\mathrm{Cys}$ to the N-terminal amine (Scheme 6). In addition, the $\mathrm{Ca}^{2+}$ ion interacts with the sulfur atom and the amide oxygen atoms after the $S-S$ bond cleavage. We suggest that the interaction between hard acid $\mathrm{Ca}^{2+}$ with the relatively soft base sulfur atom causes the process of $\mathrm{S}-\mathrm{S}$ bond cleavage to be less favorable than the $S-C$ bond cleavage [27]. As a result, highly selective $\mathrm{S}-\mathrm{C}$ bond cleavage is achieved from alkali and alkaline earth metal complexes of peptides with intermolecular disulfide bonds.

\section{The Route 66 Method for Locating Disulfide Linkages in Peptides}

Simple and fast identification of peptides with disulfide linkages in the peptic digest of insulin is demonstrated under low-energy CID conditions using $\mathrm{Na}^{+}$and $\mathrm{Ca}^{2+}$ complexes. Disulfide linkages in insulin are able to be located via further activation of the CID products. Two dipeptides, GIVEQCCASVCSL/FVNQHLCGSHL and GIVEQCCASVCSL/FVNQHLCGSHLVE, which possess one intermolecular disulfide linkage and one intramolecular disulfide linkage each, yield products evidencing the presence of disulfide linkages via CID of doubly charged $\mathrm{Na}^{+}$complexes (Figure $2 \mathrm{~b}$ and $\mathrm{c}$ ). The CID of the doubly charged disodiated peptides yields the products resulting from two $\mathrm{H}_{2} \mathrm{~S}_{2}$ eliminations. Each singly charged $\mathrm{Na}^{+}$cation may interact with each disulfide linkage to effect cleavage to yield two $\mathrm{H}_{2} \mathrm{~S}_{2}$ eliminations when the peptide complexes are collisionally activated.

As seen in Figures 3-5, higher selectivity for cleavage of $\mathrm{S}-\mathrm{C}$ bonds is observed for the $\mathrm{Ca}^{2+}$ bound complex compared with the sodiated complex via CID. The strong interaction between the amide oxygen atom at

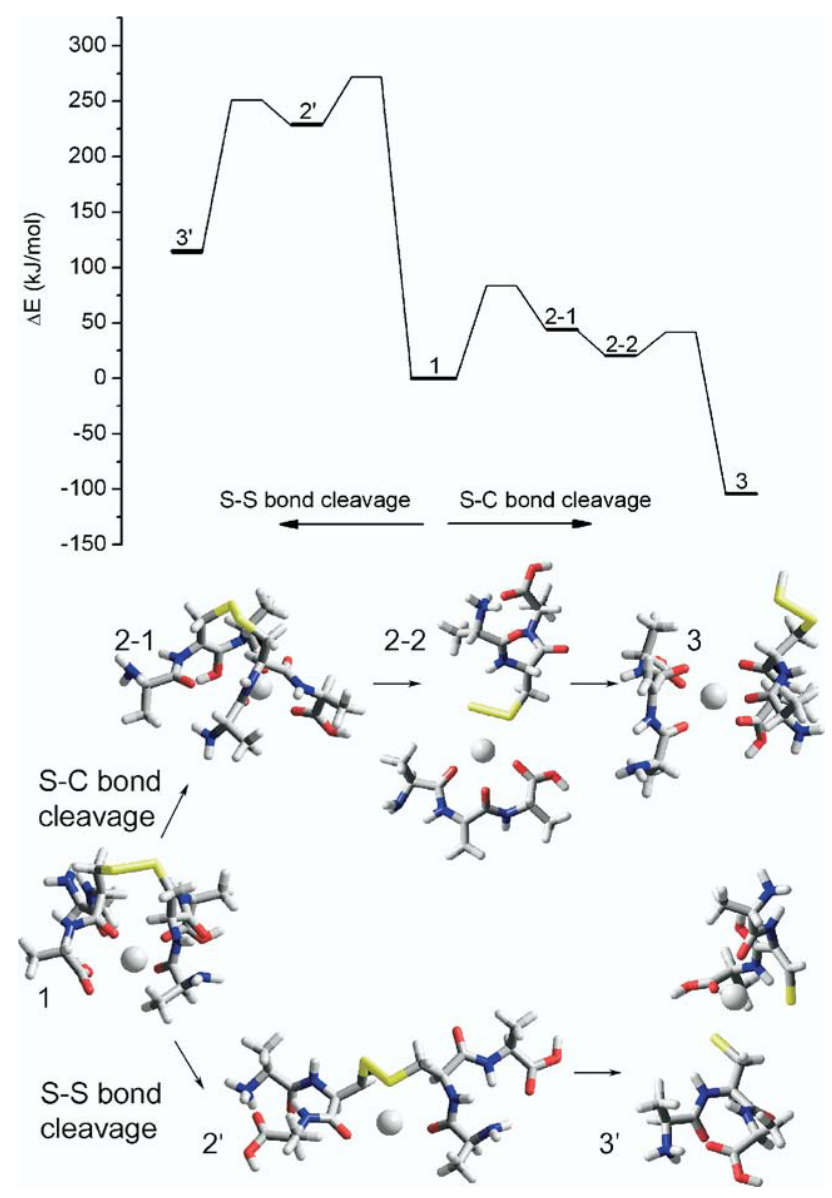

Figure 6. Reaction coordinate diagrams showing relative energies in $\mathrm{kJ} / \mathrm{mol}$ for $\mathrm{S}-\mathrm{S}$ bond cleavage (left side) and $\mathrm{S}-\mathrm{C}$ bond cleavage (right side) of doubly charged calcium bound dimeric tripeptide, $(\mathrm{ACA})_{2}$, linked by intermolecular disulfide bond at the B3LYP/LACVP level, including zero-point correction obtained at the same scaled level. Barrier heights are not known. Optimized geometries for corresponding states are obtained at the same scaled level. The reaction mechanism of each numbered step is shown in Schemes 5 and $\mathbf{6}$. 


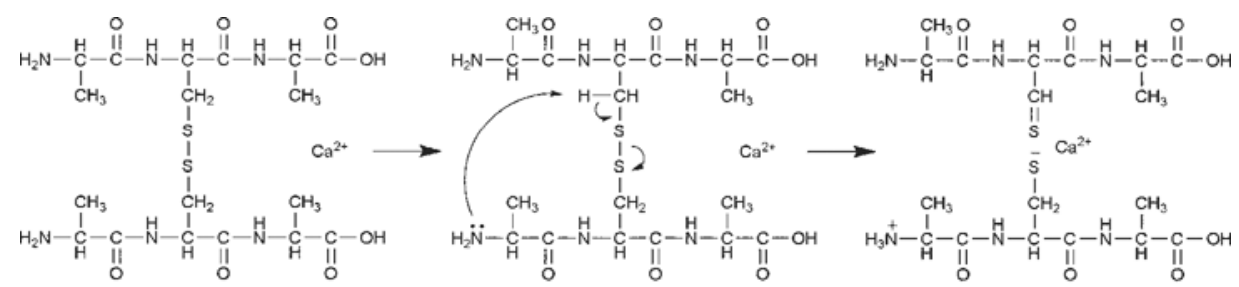

(1)

(2')

(3')

Scheme 6. The $S-S$ bond cleavage reaction of doubly charged cationic $\mathrm{Ca}^{2+}$ bound dipeptide $(\mathrm{ACA})_{2}$ linked by intermolecular disulfide bond requires a proton transfer from $\beta$-carbon at Cys. Optimized geometries and energy changes for corresponding numbered states of $\mathrm{Ca}^{2+}$ bound $(\mathrm{ACA})_{2}$ are shown in Figure 6.

Cys and divalent $\mathrm{Ca}^{2+}$ appears to facilitate enolate formation of Cys, leading in turn to highly selective $\mathrm{S}-\mathrm{C}$ bond cleavage. The $\mathrm{MS}^{3}$ spectra of products with $\mathrm{dA}$ residues allow us to identify peptides with intramolecular disulfide linkages (Figure 4b; Schemes 3 and 4). Otherwise, $\mathrm{MS}^{3}$ spectra provide sequence information of the product peptide, revealing the location of the Cys residue that forms the disulfide bond in the peptide (Schemes 2-4). For the doubly charged metal complexes with both intermolecular and intramolecular disulfide linkages, the $\mathrm{S}-\mathrm{C}$ bond cleavage occurs preferentially at the intermolecular disulfide linkage under low-energy CID conditions, the process being assisted by charge repulsion between monomeric product peptides.

\section{Conclusion}

The three disulfide linkages in insulin were characterized using mass spectrometry. The peptic digest fragments containing intermolecular disulfide linkages were easily identified from $\mathrm{MS}^{2}$ of doubly charged $\mathrm{Na}^{+}$ and $\mathrm{Ca}^{2+}$ complexes by a high abundance of paired products separated by 66 mass units. More detailed structural information for the peptide, including the location of the disulfide linkages and the presence of additional intramolecular disulfide linkages, was achieved by further activation of the product peptides to identify the position of dehydraoalanine residues. The mechanism proposed for these processes, supported by theoretical studies of model systems, involves formation of a metal-stabilized enolate at Cys, followed by cleavage of the $\mathrm{S}-\mathrm{C}$ bond. We believe that the approach described in the present and previous [12] studies, which we refer to as the Route 66 method, is a promising methodology to determine the presence and location of both inter- and intramolecular disulfide linkages in peptides and proteins.

\section{Acknowledgments}

The research described herein was carried out at the Beckman Institute and the Noyes Laboratory of Chemical Physics at the California Institute of Technology. We appreciate the support provided by the Beckman Institute Mass Spectrometry Resource Center and the Planetary Science section, Jet Propulsion Labora- tory, California Institute of Technology. Partial support was also provided by the National Science Foundation under Grant CHE0416381.

\section{References}

1. Thornton, J. M. Disulfide Bridges in Globular-Proteins. J. Mol. Biol. 1981, 151, 261-287.

2. Gorman, J. J.; Wallis, T. P.; Pitt, J. J. Protein Disulfide Bond Determination by Mass Spectrometry. Mass Spectrom. Rev. 2002, 21, 183-216.

3. Chelius, D.; Wimer, M. E. H. Reversed-Phase Liquid Chromatography In-Line with Negative Ionization Electrospray Mass Spectrometry for the Characterization of the Disulfide-Linkages of an Immunoglobulin Gamma Antibody. J. Am. Soc. Mass Spectrom. 2006, 17, 1590-1598.

4. Biemann, K.; Scoble, H. A. Characterization by Tandem Mass-Spectrometry of Structural Modifications in Proteins. Science 1987, 237, 992-998.

5. Mann, M.; Jensen, O. N. Proteomic Analysis of Post-Translational Modifications. Nat. Biotechnol. 2003, 21, 255-261.

6. Resing, K. A.; Johnson, R. S.; Walsh, K. A. Mass-Spectrometric Analysis of 21 Phosphorylation Sites in the Internal Repeat of Rat Profilaggrin Precursor of an Intermediate Filament-Associated Protein. Biochemistry 1995, 34, 9477-9487.

7. Gibson, B. W.; Cohen, P. Liquid Secondary-Ion Mass-Spectrometry of Phosphorylated and Sulfated Peptides and Proteins. Methods Enzymol. 1990, 193, 480-501.

8. Huddleston, M. J.; Annan, R. S.; Bean, M. F.; Carr, S. A. Selective Detection of Phosphopeptides in Complex-Mixtures by Electrospray Liquid-Chromatography Mass-Spectrometry. J. Am. Soc. Mass Spectrom. 1993, 4, 710-717.

9. Clauser, K. R.; Hall, S. C.; Smith, D. M.; Webb, J. W.; Andrews, L. E.; Tran, H. M.; Epstein, L. B.; Burlingame, A. L. Rapid Mass-Spectrometric Peptide Sequencing and Mass Matching for Characterization of HumanMelanoma Proteins Isolated by 2-Dimensional Page. Proc. Natl. Acad. Sci. U. S. A. 1995, 92, 5072-5076.

10. Qin, J.; Chait, B. T. Identification and Characterization of Posttranslational Modifications of Proteins by Maldi Ion Trap Mass Spectrometry. Anal. Chem. 1997, 69, 4002-4009.

11. Reid, G. E.; Roberts, K. D.; Kapp, E. A.; Simpson, R. J. Statistical and Mechanistic Approaches to Understanding the Gas-Phase Fragmentation Behavior of Methionine Sulfoxide Containing Peptides. J. Proteome Res. 2004, 3, 751-759.

12. Kim, H. I.; Beauchamp, J. L. Identifying the Presence of a Disulfide Linkage in Peptides by the Selective Elimination of Hydrogen Disulfide from Collisionally Activated Alkali and Alkaline Earth Metal Complexes. J. Am. Chem. Soc. 2008, 130, 1245-1257.

13. Gunawardena, H. P.; O'Hair, R. A. J.; McLuckey, S. A. Selective Disulfide Bond Cleavage in Gold(I) Cationized Polypeptide Ions Formed Via Gas-Phase Ion/Ion Cation Switching. J. Proteome Res. 2006, 5, 2087-2092.

14. Kleinnijenhuis, A. J.; Mihalca, R.; Heeren, R. M. A.; Heck, A. J. R. Atypical Behavior in the Electron Capture Induced Dissociation of Biologically Relevant Transition Metal Ion Complexes of the Peptide Hormone Oxytocin. Int. J. Mass Spectrom. 2006, 253, 217-224.

15. Mihalca, R.; van der Burgt, Y. E. M.; Heck, A. J. R.; Heeren, R. M. A. Disulfide Bond Cleavages Observed in Sori-Cid of Three Nonapeptides Complexed With Divalent Transition-Metal Cations. J. Mass Spectrom. 2007, 42, 450-458.

16. Lioe, H.; Duan, M.; O'Hair, R. A. J. Can Metal Ions Be Used as Gas-Phase Disulfide Bond Cleavage Reagents? A Survey of Coinage Metal Complexes of Model Peptides Containing an Intermolecular Disulfide Bond. Rapid Commun. Mass Spectrom. 2007, 21, 2727-2733.

17. Morris, H. R.; Pucci, P. A New Method for Rapid Assignment of S-S Bridges in Proteins. Biochem. Biophys. Res. Commun. 1985, 126, 11221128. 
18. Sun, Y. P.; Smith, D. L. Identification of Disulfide-Containing Peptides by Performic Acid Oxidation and Mass-Spectrometry. Anal. Biochem. 1988, 172, 130-138.

19. Wells, J. M.; Stephenson, J. L.; McLuckey, S. A. Charge Dependence of Protonated Insulin Decompositions. Int. J. Mass Spectrom. 2000, 203, A1-A9.

20. Zubarev, R. A.; Kruger, N. A.; Fridriksson, E. K.; Lewis, M. A.; Horn, D. M.; Carpenter, B. K.; McLafferty, F. W. Electron Capture Dissociation of Gaseous Multiply-Charged Proteins Is Favored at Disulfide Bonds and Other Sites of High Hydrogen Atom Affinity. J. Am. Chem. Soc. 1999, 121, 2857-2862.

21. Brown, R. S.; Lennon, J. J. Sequence-Specific Fragmentation of MatrixAssisted Laser-Desorbed Protein Peptide Ions. Anal. Chem. 1995, 67, 3990-3999.

22. Stephenson, J. L.; Cargile, B. J.; McLuckey, S. A. Ion Trap Collisional Activation of Disulfide Linkage Intact and Reduced Multiply Pro- tonated Polypeptides. Rapid Commun. Mass Spectrom. 1999, 13, 2040-2048.

23. Polfer, N. C.; Haselmann, K. F.; Zubarev, R. A.; Langridge-Smith, P. R. R. Electron Capture Dissociation of Polypeptides Using a 3 Tesla Fourier Transform Ion Cyclotron Resonance Mass Spectrometer. Rapid Commun. Mass Spectrom. 2002, 16, 936-943.

24. Becke, A. D. Density-Functional Thermochemistry. 3. The Role of Exact Exchange. J. Chem. Phys. 1993, 98, 5648-5652.

25. Lee, C. T.; Yang, W. T.; Parr, R. G. Development of the Colle-Salvetti Correlation-Energy Formula into a Functional of the Electron-Density Phys. Rev. B 1988, 37, 785-789.

26. Roepstorff, P.; Fohlman, J. Proposal for a Common Nomenclature for Sequence Ions in Mass-Spectra of Peptides. Biomed. Mass Spectrom. 1984, 11, 601-601.

27. Pearson, R. G. Hard and Soft Acids and Bases. J. Am. Chem. Soc. 1963, 85 3533-3539. 